\title{
Phase I study for ridaforolimus, an oral mTOR inhibitor, in Japanese patients with advanced solid tumors
}

\author{
Yoshitaka Seki • Noboru Yamamoto $\cdot$ Yosuke Tamura $\cdot$ Yasushi Goto $\cdot$ Takashi Shibata \\ Maki Tanioka $\cdot$ Hajime Asahina $\cdot$ Hiroshi Nokihara $\cdot$ Yasuhide Yamada $\cdot$ \\ Takashi Shimamoto $\cdot$ Kazuo Noguchi $\cdot$ Tomohide Tamura
}

Received: 11 October 2011 / Accepted: 15 November 2011 / Published online: 6 December 2011

(c) The Author(s) 2011. This article is published with open access at Springerlink.com

\begin{abstract}
Purpose Ridaforolimus is a non-prodrug mTOR inhibitor. The safety, pharmacokinetics (PK), and antitumor activity of oral ridaforolimus were assessed in Japanese patients with refractory solid tumors.

Methods Ridaforolimus (20 or $40 \mathrm{mg}$ ) was administered as a single dose on Day 1, followed by once daily dosing five times a week for a 3-week cycle beginning on Day 8 . Full PK sampling was performed on Days 1 and 26.

Results Thirteen patients ( 7 at $20 \mathrm{mg}$ and 6 at $40 \mathrm{mg}$ ) were enrolled. The median treatment duration was 82 days. The most common drug-related adverse events were stomatitis, hypertriglyceridemia, and proteinuria. Two patients had dose-limiting toxicities (grade 3 stomatitis at $20 \mathrm{mg}$, and grade 3 anorexia and vomiting at $40 \mathrm{mg}$ ). Four patients had grade 1 interstitial pneumonitis. Ridaforolimus in the whole blood was rapidly absorbed and slowly eliminated with a half-life of approximately 56-58 h after a single dose. Two patients (with non-small cell lung cancer and angiosarcoma, respectively) achieved a partial response, and five patients (one with thymic cancer and four with soft tissue sarcomas) had a stable disease for $\geq 16$ weeks.

Conclusions Ridaforolimus was well tolerated up to a dose of $40 \mathrm{mg}$ in Japanese patients. Preliminary evidence of
\end{abstract}

Y. Seki $\cdot$ N. Yamamoto $\cdot$ Y. Tamura $\cdot$ Y. Goto $\cdot$ T. Shibata

M. Tanioka $\cdot$ H. Asahina $\cdot$ H. Nokihara $\cdot$ Y. Yamada .

T. Tamura $(\bowtie)$

Division of Internal Medicine, National Cancer Center Hospital,

Tsukiji 5-1-1, Chuo-ku, Tokyo 104-0045, Japan

e-mail: ttamura@ncc.go.jp

T. Shimamoto $\cdot$ K. Noguchi

MSD K.K., Kitanomaru Square, 1-13-12, Kudan-kita,

Chiyoda-ku, Tokyo 102-8667, Japan antitumor activity was observed for patients with solid tumors. Further investigation at this dose is warranted.

Keywords Interstitial pneumonitis - mTOR inhibitor · Ridaforolimus $\cdot$ Stomatitis $\cdot$ Phase I study

\section{Introduction}

The mammalian target of rapamycin (mTOR) pathway plays a central role in the proliferation and apoptosis of cancer cells and regulates proteins critical for cell growth and division [1-3]. The phosphatidylinositol-3-kinase (PI3K) and mTOR pathways are often constitutively activated in various cancer cell types, and the mTOR pathway is a promising antitumor target. Rapamycin is the first specific mTOR inhibitor, and several mTOR analogs could be candidate antitumor agents [4-6].

Ridaforolimus (formerly deforolimus, AP23573, or MK-8669) is a novel non-prodrug rapamycin analog that is manufactured using rapamycin as a substrate [7]. In various in vitro studies, ridaforolimus inhibited mTOR activity and exhibited antiproliferative activity against a broad range of human tumor cell lines [8]. This in vitro antiproliferative activity of ridaforolimus was additive or synergistic with other cytotoxic and molecular-targeting anticancer agents, such as cisplatin, docetaxel, doxorubicin, imatinib, and trastuzumab [7]. Ridaforolimus has also shown an antitumor activity in murine tumor xenograft models using human tumor cell lines (glioblastoma, prostate cancer, breast cancer, lung cancer, colon cancer, pancreatic cancer, and various sarcomas) [9].

Ridaforolimus is currently being examined in Phase I and II trials as both a single-agent therapy and a combination therapy for non-Japanese patients with advanced 
cancers [10-15]. To date, these trials have demonstrated a favorable safety profile and activity against a broad range of malignancies, including breast cancer, endometrial cancer, hematologic malignancies, and sarcomas [16]. Based on previous Phase I/IIa clinical studies evaluating various dosing schedules in non-Japanese patients, a once daily dose of $40 \mathrm{mg}, 5$ days a week (cumulative 4-week dose of $800 \mathrm{mg}$ ), was selected for further drug evaluation.

The present Phase I study was conducted to evaluate the safety, tolerability, and pharmacokinetics of oral ridaforolimus at a once daily dose of up to $40 \mathrm{mg}, 5$ days a week, in Japanese patients and to determine the recommended dose for future studies.

\section{Materials and methods}

\section{Patient eligibility}

The main eligibility criteria were as follows: histologically (or cytologically) confirmed metastatic or locally advanced solid malignancies unresponsive to standard therapy or for which adequate standard therapy does not exist; an age of 20 years or older; an Eastern Cooperative Oncology Group performance status of 0 or 1 ; and an absolute neutrophil count $\geq 1,500 / \mu \mathrm{L}$, a platelet count $\geq 100,000 / \mu \mathrm{L}$, a hemoglobin level $\geq 9.0 \mathrm{~g} / \mathrm{dL}$, a serum creatinine level $\leq 1.5 \mathrm{mg} / \mathrm{dL}$ or a creatinine clearance $\geq 60 \mathrm{~mL} / \mathrm{min}$, a total bilirubin level $\leq 2.0 \mathrm{mg} / \mathrm{dL}$, an aspartate aminotransferase (AST) level $\leq 80 \mathrm{IU} / \mathrm{L}$, and an alanine aminotransferase (ALT) level $\leq 100 \mathrm{IU} / \mathrm{L}$. Pertinent exclusion criteria included chemotherapy, radiotherapy, or biological therapy within 4 weeks prior to enrollment; primary or unstable central nervous system metastasis; symptomatic ascites or pleural effusion requiring treatment; and a history or current evidence of pneumonitis or pulmonary infiltration. All patients provided informed consent, and the trial was conducted in accordance with current Good Clinical Practice standards.

Study design, treatment, and evaluation

An open-label, non-randomized, single-center, phase I study of ridaforolimus in patients with metastatic or locally advanced solid tumors was conducted from June 2008 to September 2009 (clinicaltrials.gov registration, NCT0069 4083). This study was conducted based on the Declaration of Helsinki and the Guidelines for Clinical Evaluation Methods of Anti-Cancer Drugs in Japan (Japanese Ministry of Health, Labour, and Welfare notification, dated November 1, 2005). This study was approved by the institutional review board of the National Cancer Center Hospital.
The first 28-day cycle was performed to evaluate doselimiting toxicities (DLTs). Patients received a single dose (20 or $40 \mathrm{mg}$ ) of ridaforolimus on Day 1, followed by a washout period of at least 6 days. Patients then received once daily dosing for five consecutive days followed by a 2-day drug rest each week from Day 8 to Day 28 as inpatients. For subsequent cycles, the patients were treated with ridaforolimus once daily, 5 days a week, in a 21-day cycle. Patients continued to receive the therapy unless they met any of the discontinuation criteria, such as disease progression or unacceptable toxicity.

Dose escalation followed a conventional " $3+3$ " design. If 1 out of 3 patients developed a DLT at dose level 1 $(20 \mathrm{mg})$ during the first cycle, three additional patients were treated at the same dose level, for a total of six patients. If either $0 / 3$ or $1 / 6$ patients developed a DLT at dose level 1 , the study progressed to dose level $2(40 \mathrm{mg})$. If two or more patients developed DLTs, the dose was not escalated to level 2. At dose level 2, a toxicity evaluation was also performed for six patients.

Toxicity was graded and recorded according to the National Cancer Institute-Common Terminology Criteria for Adverse Events (CTCAE), version 3.0, and DLT was defined as any of the following events judged to be related to the study drug (i.e., classified as possibly related, probably related, or definitely related) during the first cycle (DLT evaluation period): Grade 4 neutropenia persisting for $>5$ days, Grade 3 or 4 neutropenia associated with fever (temperature $>38.5^{\circ} \mathrm{C}$ ), Grade 4 thrombocytopenia, Grade 3 or Grade 4 non-hematologic toxicity (except for alopecia, toxicities controllable with appropriate supportive care, and transient electrolyte abnormalities).

Antitumor activity was investigated in an exploratory fashion based on RECIST, version 1.0.

\section{Pharmacokinetic assessment}

The ridaforolimus concentration in the whole blood and plasma and the pharmacokinetic parameters were evaluated during the first treatment cycle. Blood samples were collected according to the following sampling schedule: predose and $0.5,1.0,2.0,4.0,8.0,24,72,96$, and $168 \mathrm{~h}$ postdose on Day 1; predose on Days 15, 18, 22, and 23, and predose and $0.5,1.0,2.0,4.0,8.0$, and $24 \mathrm{~h}$ postdose on Day 26. Ridaforolimus in the whole blood and plasma was analyzed using high-performance liquid chromatography with tandem mass spectrometric detection. The apparent terminal $t_{1 / 2}$ was estimated from the best-fit variables to the log-linear portion of the blood concentration-time curve using an unweighted linear regression. The area under the curve over the first $24 \mathrm{~h}\left(\mathrm{AUC}_{0-24 \mathrm{~h}}\right)$ was calculated using the linear up/log down trapezoidal method up to $24 \mathrm{~h}$ postdose. $T_{\max }, C_{\max }$, and $C_{\text {trough }}$ were obtained by inspecting 
the concentration-time data. To assess the accumulation of ridaforolimus in the whole blood, individual whole blood $\mathrm{AUC}_{0-24 \mathrm{~h}}$ values (from subjects evaluated on both days only) were natural log-transformed and evaluated using a linear mixed effects model with fixed effects for dose and day (Day 1, Day 26), dose-by-day interaction, and a random effect for subject. The geometric means and $95 \%$ confidence intervals of the $\mathrm{AUC}_{0-24 \mathrm{~h}}, C_{\max }$, and $C_{\text {trough }}$ were calculated for each dose and day using this model. The geometric mean accumulation ratios (Day 26/Day 1) and the 90\% confidence intervals for these parameters were also calculated from the model for each dose.

\section{Results}

\section{Patient characteristics}

Thirteen Japanese patients with solid tumors were enrolled and were evaluated in this study. The baseline characteristics of the patients are summarized in Table 1. The age range was 26-68 years (median: 54 years). Seven patients had sarcomas. The median number of prior chemotherapy regimens was 3 (range: $0-12$ ). One patient treated at dose level $1(20 \mathrm{mg})$ was excluded from the DLT evaluation because the achieved dose intensity was $<75 \%$ of the scheduled dose; this patient developed tumor-associated pneumonia, which was unrelated to the study drug. Therefore, one new patient was added, making a total of seven patients treated at dose level 1. Six patients were treated at dose level $2(40 \mathrm{mg})$. The median treatment duration was 35.0 days at dose level 1 and 88.5 days at dose level 2 . None of the patients treated at dose level 2 required a dose reduction. The longest treatment duration was 234 days achieved in one patient who was treated at dose level 2. Six patients discontinued treatment because of adverse events, and seven discontinued treatment because of progressive disease.

\section{Safety evaluation}

A summary of the DLTs is given in Table 2. As noted, one of the seven patients treated at dose level $1(20 \mathrm{mg})$ was excluded from the evaluation. Of the six patients who were evaluated at dose level 1, one patient developed Grade 3 stomatitis. In addition, one of the six patients evaluated for DLTs at dose level $2(40 \mathrm{mg})$ developed Grade 3 anorexia and Grade 3 vomiting. The time until the onset of the DLT after the administration of ridaforolimus was 8 days for the Grade 3 stomatitis and 23 days for both the Grade 3 anorexia and the Grade 3 vomiting. All the DLTs were manageable with medical treatment or the discontinuation of
Table 1 Baseline characteristics of the subjects

\begin{tabular}{ll}
\hline Characteristic & $N=13$ \\
\hline Age, year (range) & $54(26-68)$ \\
Male/female & $6 / 7$ \\
Weight, kg & $60.0(37.9-97.8)$ \\
Performance status 0/1 & $9 / 4$ \\
Prior therapy & \\
Chemotherapy & 12 \\
Number of previous regimens, median (range) & $3(0-12)$ \\
Surgery & 12 \\
Radiation & 5 \\
Tumor type & \\
Non-small cell lung cancer & 5 \\
Osteosarcoma & 2 \\
Liposarcoma & 2 \\
Leiomyosarcoma & 2 \\
Renal angiosarcoma & 1 \\
Thymic cancer & 1 \\
\hline
\end{tabular}

Table 2 Summary of dose-limiting toxicities (DLTs) (Cycle 1)

\begin{tabular}{lllll}
\hline $\begin{array}{l}\text { Dose } \\
\text { level }\end{array}$ & $\begin{array}{l}\text { Dose } \\
(\mathrm{mg})\end{array}$ & $\mathrm{n} / \mathrm{N}^{\mathrm{a}}$ & DLTs & $\begin{array}{l}\text { Time to } \\
\text { onset (days) }\end{array}$ \\
\hline Level 1 & 20 & $1 / 6^{\mathrm{b}}$ & Grade 3 stomatitis & 8 \\
Level 2 & 40 & $1 / 6$ & $\begin{array}{l}\text { Grade 3 anorexia } \\
\text { Grade 3 vomiting }\end{array}$ & 23 \\
\hline
\end{tabular}

${ }^{a} n / N$ No. of patients with DLT/No. of patients at the dose level

${ }^{\mathrm{b}}$ One patient was excluded from the DLT evaluation

ridaforolimus, and the patients recovered to $\leq$ Grade 1 within 3 to 10 days.

The common clinical and laboratory adverse events detected in all the treatment cycles are summarized in Table 3. The most common clinical adverse events related to ridaforolimus treatment were stomatitis (13/13: 100\%), hypertriglyceridemia (9/13: 69.2\%), skin rash (6/13: 61.5\%), hypercholesterolemia $(6 / 13: 46.2 \%)$, and proteinuria $(6 / 13$ : 46.2\%). The most common hematological adverse events were thrombocytopenia $(5 / 13: 38.5 \%)$, leucopenia (4/13: $30.8 \%)$, and neutropenia (4/13: $30.8 \%)$.

Four patients were diagnosed as having drug-induced interstitial pneumonitis based on independent reviews of chest X-ray films or CT scans, but none of the patients were symptomatic (Grade 1). Three of the four patients were managed with treatment interruption, while one patient continued to receive treatment without dose modification. The pneumonitis resolved in all the patients by the end of the study. 
Table 3 Common drug-related adverse events in all cycles $(>30 \%)$

\begin{tabular}{|c|c|c|c|c|c|c|}
\hline & \multicolumn{2}{|c|}{$20 \mathrm{mg}(n=7)$} & \multicolumn{2}{|c|}{$40 \mathrm{mg}(n=6)$} & \multicolumn{2}{|c|}{ All patients $(n=13)$} \\
\hline & Grades $1-2$ & Grades 3-4 & Grades $1-2$ & Grades 3-4 & Grades $1-2$ & Grades 3-4 \\
\hline \multicolumn{7}{|l|}{ Hematologic } \\
\hline Anemia & 1 & 1 & 3 & 3 & 1 & 4 \\
\hline Thrombocytopenia & 2 & 0 & 3 & 0 & 5 & 0 \\
\hline Neutropenia & 1 & 2 & 1 & 0 & 2 & 2 \\
\hline Leukopenia & 1 & 1 & 2 & 0 & 3 & 1 \\
\hline \multicolumn{7}{|l|}{ Non-hematologic } \\
\hline Stomatitis & 7 & 1 & 6 & 0 & 12 & 1 \\
\hline Hypertriglyceridemia & 5 & 0 & 4 & 0 & 9 & 0 \\
\hline Proteinuria & 3 & 0 & 3 & 0 & 6 & 0 \\
\hline Hypercholesterolemia & 3 & 0 & 3 & 0 & 6 & 0 \\
\hline Rash & 5 & 0 & 2 & 1 & 5 & 1 \\
\hline Anorexia & 2 & 0 & 2 & 1 & 4 & 1 \\
\hline Hyperglycemia & 2 & 0 & 2 & 1 & 4 & 1 \\
\hline Hypoalbuminemia & 2 & 0 & 3 & 0 & 5 & 0 \\
\hline Constipation & 3 & 0 & 1 & 0 & 4 & 0 \\
\hline Fatigue & 1 & 0 & 3 & 0 & 4 & 0 \\
\hline Loss of body weight & 0 & 0 & 4 & 0 & 4 & 0 \\
\hline Interstitial pneumonitis & 1 & 0 & 3 & 0 & 4 & 0 \\
\hline
\end{tabular}

Pharmacokinetic evaluation

The pharmacokinetic parameters (evaluated during cycle 1) are summarized in Table 4. Ridaforolimus exhibited a lag time of 1-4 h on Day 1 for systemic absorption, i.e., the whole blood concentration was below the quantitation limit $(<0.2 \mathrm{ng} / \mathrm{mL})$ for $2-4 \mathrm{~h}$ after the administration of $20 \mathrm{mg}$ and for $1-2 \mathrm{~h}$ after the administration of $40 \mathrm{mg}$. The $C_{\max }$ was reached approximately $4 \mathrm{~h}$ after administration on Days 1 and 26, although the median $T_{\max }$ was $7.93 \mathrm{~h}$ on Day 1 after a dose of $20 \mathrm{mg}$. The whole blood concentration declined in a bi-exponential manner, and the apparent terminal-phase half-life $\left(t_{1 / 2}\right)$ (obtained at up to $168 \mathrm{~h}$ after a single dose on Day 1 ) ranged from 55.8 to $58.0 \mathrm{~h}$ (harmonic mean). Because of this long $t_{1 / 2}$, the value could not be calculated on Day 26 because the blood samples were only collected for $24 \mathrm{~h}$ after administration.

The mean whole blood $C_{\text {trough }}$ values tended to reach a steady state after about 1 week of ridaforolimus administration, with moderate accumulation (i.e., an increase of less than or approximately twofold from Day 1 to Day 26) observed based on the $\mathrm{AUC}_{0-24 \mathrm{~h}}, C_{\max }$, and $C_{\text {trough }}$ values. The plasma concentration of ridaforolimus was substantially lower than the whole blood concentration, indicating a high blood-to-plasma ratio.

\section{Efficacy evaluation}

The response to oral ridaforolimus and the duration of antitumor activity are summarized in Table 5.
Table 4 Whole blood pharmacokinetic parameters of ridaforolimus

\begin{tabular}{|c|c|c|c|}
\hline Parameters & Day & $\begin{array}{l}\text { Dose level } 1 \\
20 \mathrm{mg}(n=7)\end{array}$ & $\begin{array}{l}\text { Dose level } 2 \\
40 \mathrm{mg}(n=6)\end{array}$ \\
\hline \multirow{2}{*}{$\begin{array}{l}\mathrm{AUC}_{0-24 \mathrm{~h}} \\
\quad(\mathrm{ng} \mathrm{h} / \mathrm{mL})^{\mathrm{a}}\end{array}$} & 1 & $1,100(721,1,680)$ & $1,470(914,2,360)$ \\
\hline & 26 & $1,670(1,090,2,550)^{\mathrm{e}}$ & $2,120(1,320,3,410)^{\mathrm{f}}$ \\
\hline \multirow[t]{2}{*}{$C_{\max }(\mathrm{ng} / \mathrm{mL})^{\mathrm{a}}$} & 1 & $113(73.3,175)$ & $187(115,304)$ \\
\hline & 26 & $155(101,240)^{\mathrm{e}}$ & $188(116,306)^{\mathrm{f}}$ \\
\hline \multirow[t]{2}{*}{$T_{\max }(\mathrm{h})^{\mathrm{b}}$} & 1 & $7.93(3.90,23.9)$ & $4.00(4.00,8.00)$ \\
\hline & 26 & $4.00(3.98,4.00)^{\mathrm{e}}$ & $4.04(4.00,8.15)^{\mathrm{f}}$ \\
\hline \multirow[t]{2}{*}{$t_{1 / 2}(\mathrm{~h})^{\mathrm{c}}$} & 1 & $58.0 \pm 8.27$ & $55.8 \pm 4.85$ \\
\hline & 26 & - & - \\
\hline \multicolumn{4}{|c|}{ Accumulation ratio (Day 26/Day 1$)^{\mathrm{d}}$} \\
\hline \multicolumn{2}{|l|}{$\mathrm{AUC}_{0-24 \mathrm{~h}}$} & $1.51(1.14,2.01)$ & $1.44(1.05,1.99)$ \\
\hline \multicolumn{2}{|l|}{$C_{\max }$} & $1.37(0.959,1.97)$ & $1.01(0.674,1.50)$ \\
\hline \multicolumn{2}{|l|}{$C_{\text {trough }}$} & $2.02(1.61,2.52)$ & $1.76(1.37,2.25)$ \\
\hline
\end{tabular}

${ }^{\mathrm{a}}$ Geometric mean (95\% confidence interval), ${ }^{\mathrm{b}}$ Median (min, max), ${ }^{\mathrm{c}}$ Harmonic mean (jack-knife SD), ${ }^{\mathrm{d}}$ Geometric mean ratio (90\% coxnfidence interval), ${ }^{\mathrm{e}} N=5,{ }^{\mathrm{f}} N=4$

Two patients achieved a partial response: one patient with non-small cell lung cancer (NSCLC) and one patient with angiosarcoma (Fig. 1). The time until the response was 28 days for both patients. The duration of the response and the time-to-progression (TTP) were 212 and 240 days, respectively, for the patient with NSCLC, who was treated at dose level 1 (20 mg). The response duration and the TTP were not calculated for the patient with the angiosarcoma because this patient discontinued the treatment in response 
Table 5 Antitumor activity of ridaforolimus
$P R$ partial response, $S D$ stable disease, $P D$ progressive disease, $N S C L C$ non-small cell lung cancer

\begin{tabular}{|c|c|c|c|c|c|}
\hline $\begin{array}{l}\text { Patient } \\
\text { number }\end{array}$ & Tumor type & Dose & $\begin{array}{l}\text { No. of prior } \\
\text { regimens }\end{array}$ & $\begin{array}{l}\text { Best } \\
\text { response }\end{array}$ & $\begin{array}{l}\text { Duration of } \\
\text { stable disease } \\
\text { (weeks) }\end{array}$ \\
\hline 1 & Osteosarcoma & $20 \mathrm{mg}$ & 5 & SD & 3.7 \\
\hline 2 & NSCLC (adenocarcinoma) & & 3 & PD & - \\
\hline 3 & Thymic cancer & & 4 & SD & 16.3 \\
\hline 4 & NSCLC (squamous cell carcinoma) & & 3 & PR & - \\
\hline 5 & Liposarcoma & & 1 & $\mathrm{SD}$ & 16.1 \\
\hline 6 & NSCLC (adenocarcinoma) & & 5 & SD & 4.0 \\
\hline 7 & NSCLC (adenocarcinoma) & & 1 & SD & 4.0 \\
\hline 8 & Osteosarcoma & $40 \mathrm{mg}$ & 6 & SD & 4.0 \\
\hline 9 & Liposarcoma & & 0 & SD & 17.3 \\
\hline 10 & Leiomyosarcoma & & 5 & SD & 16.3 \\
\hline 11 & Leiomyosarcoma & & 1 & SD & 17.1 \\
\hline 12 & NSCLC (adenocarcinoma) & & 12 & PD & - \\
\hline 13 & Renal angiosarcoma & & 1 & PR & - \\
\hline
\end{tabular}

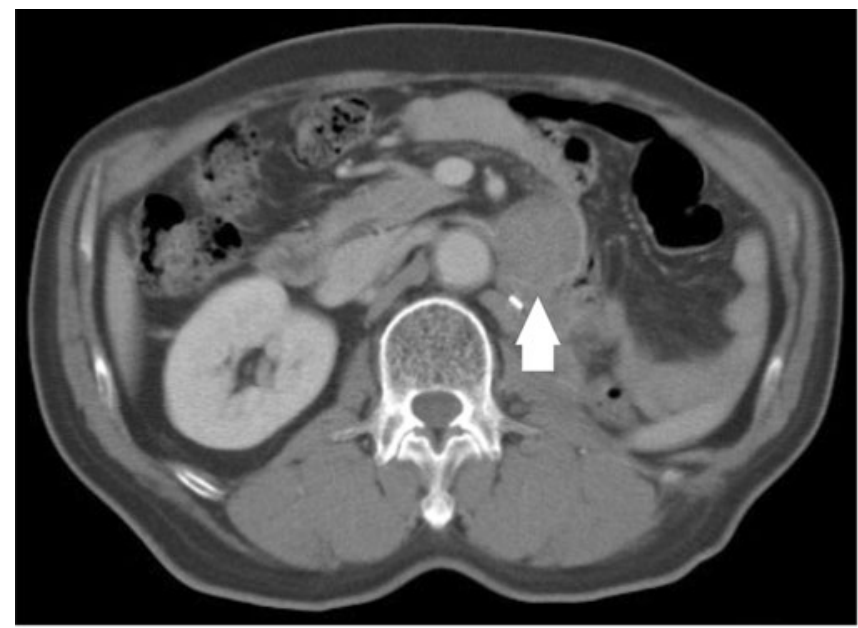

a

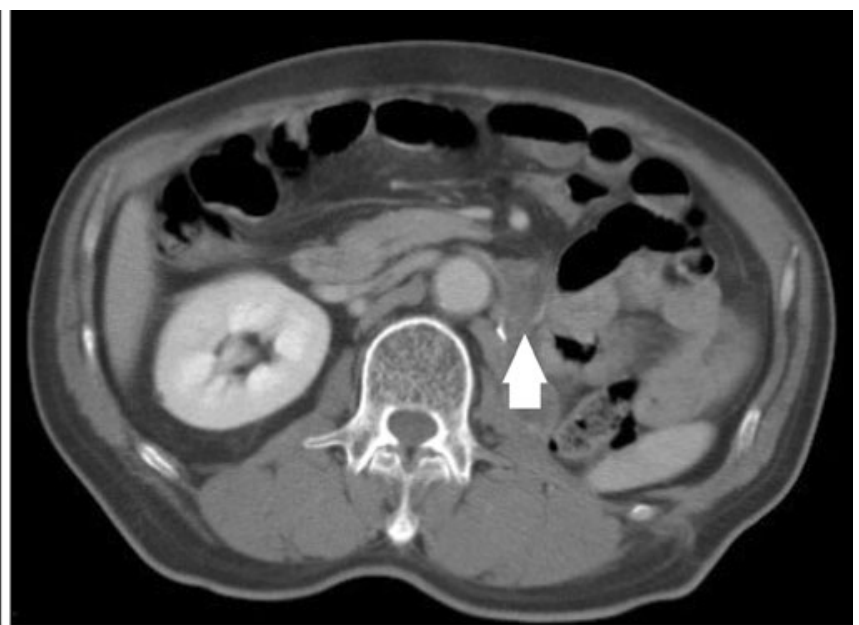

b

Fig. 1 CT scans showing a partial response (in Patient 13). a Baseline, longest diameter of $42 \mathrm{~mm}$; and b Day 28, longest diameter of $21 \mathrm{~mm}$

to an adverse event. Five patients exhibited stable disease for longer than 16 weeks.

\section{Discussion}

The primary objective of the present study was to confirm the safety and tolerability of ridaforolimus in Japanese patients with advanced solid tumors for whom standard treatment had failed. The initial dose was set at half the maximum tolerated dose (MTD) in previous Phase I clinical studies and the optimal dose in Phase II clinical studies in which various dosing schedules were studied in non-Japanese patients [10-13]. The administration regimen for this study was selected to enable a greater cumulative 4-week dose. The MTD using a once daily, five-times-a-week regimen was $40 \mathrm{mg}$, and the cumulative 4-week dose was $800 \mathrm{mg}$ in non-Japanese patients, whereas the MTD using a daily regimen was $10 \mathrm{mg}$ and the cumulative dose was $280 \mathrm{mg}$ in non-Japanese patients. Two days of dose "rest" facilitated a higher cumulative AUC and greater tolerability than continuous daily dosing. In addition, the long half-life enabled intermittent dosing. Therefore, a $40 \mathrm{mg}$ dose administered five times a week was selected as the recommended dose and schedule.

In general, oral ridaforolimus (40 mg daily, five times a week) exhibited an acceptable safety profile in Japanese patients with advanced solid tumors. Most of the common symptomatic adverse events in the present study were also reported for orally or intravenously administered ridaforolimus 
in non-Japanese patients. Based on the above findings, the overall safety profile of ridaforolimus in Japanese patients with advanced solid tumors in the present study was generally consistent with that observed previously in phase I/IIa studies in non-Japanese patients with refractory or advanced solid tumors. The PK profiles of ridaforolimus in the Japanese patients did not differ from the internal PK data obtained in non-Japanese patients with advanced solid tumors (data not shown).

One patient at dose level $1(20 \mathrm{mg})$ experienced a DLT (Grade 3 stomatitis), and one patient at dose level $2(40 \mathrm{mg})$ experienced two DLTs (Grade 3 anorexia and Grade 3 vomiting). All of the DLTs were reversible and were promptly resolved after the completion of the study drug administration. In the previous Phase I/IIa clinical study performed in non-Japanese patients with refractory or advanced solid cancer, the DLTs noted for the same dosing schedule ( $40 \mathrm{mg}$ daily, five times a week) were stomatitis and fatigue [17].

Stomatitis was seen in all 13 patients enrolled in this study and has been commonly reported as a drug-related adverse event in other clinical studies examining ridaforolimus. The stomatitis lesions consisted of aphthous-like mouth sores that were distinct from chemotherapy-associated mucositis. In the present study, the median time until the onset of stomatitis was 11 days, indicating that this toxicity occurs relatively soon after the start of ridaforolimus administration. Most cases resolved after dose interruption or discontinuation. Preventive measures such as oral care, local analgesia, and other supportive therapies should be considered during the administration of ridaforolimus. Stomatitis and mucosal inflammation have also been commonly reported in association with other mTOR inhibitors, such as everolimus and temsirolimus [18-21].

The incidence of interstitial pneumonitis was higher in the present report than in previous studies examining ridaforolimus [11]. However, all the cases were mild, asymptomatic, and limited to imaging changes (Grade 1), and all the patients had recovered by the end of the study period. These events occurred at 2-5 months after the start of treatment. The findings were consistent with the results of a study examining the mTOR inhibitor everolimus in Japanese patients with advanced renal cell carcinoma; the incidence of pneumonitis in this previous study was $27 \%$, which was higher than the $11 \%$ overall rate reported in patients with renal cell carcinoma [18]. Because of the small number of patients in each study, however, whether this incidence was related to ethnicity remains uncertain. The relatively high incidence might also result from more intensive monitoring for lung injuries because of the increased rates of interstitial pneumonitis, bronchiolitis obliterans, and persistent organizing pneumonia that are observed when mTOR inhibitors are used [22]. Accord- ingly, pulmonary opacities on chest radiographs should be carefully distinguished from progressive metastatic disease, and pulmonary symptoms should be carefully monitored. Notably, there were five patients with NSCLC in this study. Interstitial pneumonitis occurred in one of these five NSCLC patients, whereas the other three cases occurred among eight patients with other cancer types, suggesting that the incidence of interstitial pneumonitis did not differ between patients with lung cancer and non-lung cancer patients.

Our exploratory analysis of efficacy revealed a partial response in two patients (NSCLC and renal angiosarcoma), and five patients exhibited stable disease for longer than 16 weeks. These results suggest that ridaforolimus may be active against advanced solid tumors, including sarcoma. Ridaforolimus has also demonstrated clinical activity against sarcomas and other cancers, including endometrial cancer [23], and is currently being studied as a maintenance treatment for soft tissue and bone sarcomas. In addition, a Phase II study of ridaforolimus used in combination with insulin-like growth factor-1 inhibitor (IGF-1) for breast cancer is underway. Importantly, in a recent Phase III sarcoma maintenance study [24], ridaforolimus met the prespecified study endpoint of a statistically significant improvement in progression-free survival, compared with a placebo group (hazard ratio $=0.72, P=0.0001$, stratified log-rank).

In conclusion, the safety and tolerability of ridaforolimus at a dose of up to $40 \mathrm{mg}$ were confirmed in Japanese patients, and an exploratory efficacy analysis supported the usefulness of ridaforolimus for the treatment of advanced solid tumors. Additional studies are ongoing to confirm the safety and efficacy of ridaforolimus.

Acknowledgments We would like to thank Masahiko Kusumoto, MD (National Cancer Center Hospital, Tokyo, Japan) for performing the chest CT evaluations. Research funding was provided by Merck \& Co., Inc. (Whitehouse Station, NJ, USA) and MSD K.K. (Tokyo, Japan). We would like to thank Steven Smugar (Merck \& Co., Inc.) for providing medical writing and editing.

Open Access This article is distributed under the terms of the Creative Commons Attribution Noncommercial License which permits any noncommercial use, distribution, and reproduction in any medium, provided the original author(s) and source are credited.

\section{References}

1. Bjornsti MA, Houghton PJ (2004) The TOR pathway: a target for cancer therapy. Nat Rev Cancer 4:335-348. doi:10.1038/nrc1362

2. Adjei AA, Hidalgo M (2005) Intracellular signal transduction pathway proteins as targets for cancer therapy. J Clin Oncol 23:5386-5403. doi:10.1200/JCO.2005.23.648

3. Clackson T, Metcalf CA, Rivera VM, et al (2003) Broad anti-tumor activity of ap23573, an mTOR inhibitor in clinical development. Am Soc Clin Oncol (Meeting Proceedings) 22:220, abstr 882 
4. Vilella-Bach M, Nuzzi P, Fang Y, Chen J (1999) The FKBP ${ }_{12^{-}}$ rapamycin-binding domain is required for $\mathrm{FKBP}_{12}$-rapamycinassociated protein kinase activity and $\mathrm{G}_{1}$ progression. $\mathrm{J}$ Biol Chem 274:4266-4272. doi:10.1074/jbc.274.7.4266

5. Faivre S, Kroemer G, Raymond E (2006) Current development of mTOR inhibitors as anticancer agents. Nat Rev Drug Discov 5:671-688. doi:10.1038/nrd2062

6. Semenza GL (2003) Targeting HIF-1 for cancer therapy. Nat Rev Cancer 3:721-732. doi:10.1038/nrc1187

7. Vignot S, Faivre S, Aguirre D, Raymond E (2005) mTOR-targeted therapy of cancer with rapamycin derivatives. Ann Oncol 16:525537. doi:10.1093/annonc/mdil13

8. Shaw RJ, Cantley LC (2006) Ras, PI(3)K and mTOR signalling controls tumour cell growth. Nature 441:424-430. doi:10.1038/ nature 04869

9. Fasolo A, Sessa C (2008) mTOR inhibitors in the treatment of cancer. Expert Opin Investig Drugs 17:1717-1734. doi:10.1517/ 13543784.17.11.1717

10. Mita MM., Britten CD, Poplin E, Tap WD, Carmona A, Yonemoto L, Wages DS, Bedrosian CL, Rubin EH, Tolcher AW (2008) Deforolimus trial 106: a phase I trial evaluating 7 regimens of oral deforolimus (AP23573; MK-8669). J Clin Oncol 26(Suppl):abstr 3509

11. Mita MM, Mita AC, Chu QS, Rowinsky EK, Fetterly GJ, Goldston M, Patnaik A, Mathews L, Ricart AD, Mays T, Knowles H, Rivera VM, Kreisberg J, Bedrosian CL, Tolcher AW (2008) Phase I trial of the novel mammalian target of rapamycin inhibitor deforolimus (AP23573; MK-8669) administered intravenously daily for 5 days every 2 weeks to patients with advanced malignancies. J Clin Oncol 26:361-367. doi:10.1200/JCO.2007.12.0345

12. Hartford CM, Desai AA, Janisch L, Karrison T, Rivera VM, Berk L, Loewy JW, Kindler H, Stadler WM, Knowles HL, Bedrosian C, Ratain MJ (2009) A phase I trial to determine the safety, tolerability, and maximum tolerated dose of deforolimus in patients with advanced malignancies. Clin Cancer Res 15:1428-1434. doi:10.1158/1078-0432.CCR-08-2076

13. Rizzieri DA, Feldman E, Dipersio JF, Gabrail N, Stock W, Strair R, Rivera VM, Albitar M, Bedrosian CL, Giles FJ (2008) A phase 2 clinical trial of deforolimus (AP23573, MK-8669), a novel mammalian target of rapamycin inhibitor, in patients with relapsed or refractory hematologic malignancies. Clin Cancer Res 14:27562762. doi: 10.1158/1078-0432.CCR-07-1372

14. Perotti A, Locatelli A, Sessa C, Hess D, Viganò L, Capri G, Maur M, Cerny T, Cresta S, Rojo F, Albanell J, Marsoni S, Corradino I, Berk L, Rivera VM, Haluska F, Gianni L (2010) Phase IB study of the mTOR inhibitor ridaforolimus with capecitabine. J Clin Oncol 28:4554-4561. doi:10.1200/JCO.2009.27.5867
15. Sessa C, Tosi D, Viganò L, Albanell J, Hess D, Maur M, Cresta S, Locatelli A, Angst R, Rojo F, Coceani N, Rivera VM, Berk L, Haluska F, Gianni L (2010) Phase Ib study of weekly mammalian target of rapamycin inhibitor ridaforolimus (AP23573; MK-8669) with weekly paclitaxel. Ann Oncol 21:1315-1322. doi:10.1093/ annonc/mdp504

16. Wan X, Helman LJ (2007) The biology behind mTOR inhibition in sarcoma. Oncologist 12:1007-1018. doi:10.1634/theoncologist.12-8-1007

17. Sonis S, Treister N, Chawla S, Demetri G, Haluska F (2010) Preliminary characterization of oral lesions associated with inhibitors of mammalian target of rapamycin in cancer patients. Cancer 116:210-215. doi:10.1002/cncr.24696

18. Tsukamoto T, Shinohara N, Tsuchiya N, Hamamoto Y, Maruoka M, Fujimoto H, Niwakawa M, Uemura H, Usami M, Terai A, Kanayama H, Sumiyoshi Y, Eto M, Akaza H (2011) Phase III trial of everolimus in metastatic renal cell carcinoma: subgroup analysis of Japanese patients from RECORD-1. Jpn J Clin Oncol 41:1724. doi:10.1093/jjco/hyq166

19. Doi T, Muro K, Boku N, Yamada Y, Nishina T, Takiuchi H, Komatsu Y, Hamamoto Y, Ohno N, Fujita Y, Robson M, Ohtsu A (2010) Multicenter phase II study of everolimus in patients with previously treated metastatic gastric cancer. JClin Oncol 28:1904-1910. doi:10.1200/JCO.2009.26.2923

20. Okamoto I, Doi T, Ohtsu A, Miyazaki M, Tsuya A, Kurei K, Kobayashi K, Nakagawa K (2010) Phase I clinical and pharmacokinetic study of RAD001 (everolimus) administered daily to Japanese patients with advanced solid tumors. Jpn J Clin Oncol 40:1723. doi:10.1093/jjco/hyp120

21. Fujisaka Y, Yamada Y, Yamamoto N, Horiike A, Tamura T (2010) A Phase 1 clinical study of temsirolimus (CCI-779) in Japanese patients with advanced solid tumors. Jpn J Clin Oncol 40:732-738. doi:10.1093/jjco/hyq047

22. Kahn DY, Mita AC, George BJ, et al (2010) Mammalian target of rapamycin (mTOR)-induced pneumonitis: single-institution experience and treatment. J Clin Oncol 28(Suppl):abstr e13520

23. Colombo N, McMeekin S, Schwartz P, et al (2007) A phase II trial of the mTOR inhibitor AP23573 as a single agent in advanced endometrial cancer. Am Soc Clin Oncol (Meeting Proceedings) 25:18(Suppl), abstr 5516

24. Chawla SP, Blay J, Ray-Coquard IL, et al (2011) Results of the phase III, placebo-controlled trial (SUCCEED) evaluating the mTOR inhibitor ridaforolimus (R) as maintenance therapy in advanced sarcoma patients (pts) following clinical benefit from prior standard cytotoxic chemotherapy (CT). J Clin Oncol 29(Suppl):abstr 10005 